\title{
Transformation of the Structure of Self-Attitude in Early, Middle and Later Adulthood (on the Example of the Ukrainian Sample)
}

\author{
Mychailo V. Kostytsky ${ }^{1}$, Nataliia V. Kushakova-Kostytska ${ }^{1, *}$, Olena D. Glavinska ${ }^{2}$, \\ Vilena O. Kit ${ }^{3}$ and Inna M. Leonova ${ }^{4}$ \\ ${ }^{1}$ National Academy of Internal Affairs, 1 Solomyanska Sq., Kyiv, 103035, Ukraine \\ ${ }^{2}$ Rivne State University of the Humanitarians, 12, Stepan Bandera str., Rivne 0362, Ukraine \\ ${ }^{3}$ Ternopil Volodymyr Hnatiuk National Pedagogical University, 2, M. Kryvonosa St., Ternopil, 46027, Ukraine \\ ${ }^{4}$ Taras Shevchenko National University of Kyiv, 2a, Academician Glushkov Ave., Kyiv, 03680, Ukraine
}

\begin{abstract}
The study intends to trace the dynamics of self-esteem and changes in the structure of self-attitude at different stages of adult life, as well as identify signs of experiencing age-related crises. Self-attitude is considered a multidimensional formation, with its individual components, have different subjective significance in different periods of life. A cross-section was carried out in 507 subjects aged 25-65 years was carried out. Rosenberg Self-Esteem Scale and Self-Attitude Study Methodology by Pantileev were used. Normative data for RSES obtained on a sample of adult Ukrainians $(\mathrm{N}=488)$ are presented for the first time. The average interval was $22.70 \pm 5.43$ (with a measuring scale of 0 to 30 points), but the reference point for low self-esteem is different for men and women. Comparison of average results in groups belonging to periods of early, middle, and later adulthood showed that the attitude towards oneself with age becomes more emotionally expressive, concerning both positive and negative components. The indicators of self-blame and inner closedness grow along with the growth of the positive self-attitude (self-confidence, self-management, selfacceptance). The heterogeneous age dynamics of components of self-attitude, pronounced peaks, and dips in different periods are shown. Based on the clustering of empirical data, we described seven types of self-attitude in adulthood: illusory, confident, accepting, crisis, externally oriented, persistently negative, and inexpressive. Markers of experiencing crisis life periods are the ambivalence of self-attitude - the simultaneous manifestation of positive and negative components, which is regarded as a sign of instability. The obtained results demonstrate that there are potential opportunities for personal growth among cases of low self-esteem.
\end{abstract}

Keywords: Self-attitude, self-esteem, instability of self-esteem, structure of self-attitude, protection of a positive self-concept, age crisis.

\section{INTRODUCTION}

Self-attitude is one of the core features of an individual. Most of the life successes, social processes, and psychological problems of a person can be reduced to this concept or explained with it. One article cannot cover numerous theories on the nature and genesis of self-attitude, its conscious and unconscious components, situational dynamics, and role in human life. It is generally accepted today to understand selfattitude as a stable personal education - a generalized self-image integrated from particular self-esteem. The term "self-attitude" is a generic term in relation to the numerous components of self-concept, which has the prefix "self": self-feeling, self-esteem, self-efficacy, selfimage, self-confidence, self-regard, self-acceptance, and others. Terminological uncertainty gives rise to discussions about the differentiation of the terms "selfesteem", "self-attitude", and "self-concept" [1].

${ }^{*}$ Address correspondence to this author at the National Academy of Internal Affairs, 1 Solomyanska Sq., Kyiv, 103035, Ukraine; Tel: + 38 (044) 520 0666; Fax: + 38 (044) 24568 97; E-mail: natalia.teaching1979@gmail.com
In a one-dimensional approach, self-attitude is considered as an integrated experience of a person's own value, which is formed in a particular social environment and forms further relationships with the world (personal theories of reality): global self-esteem by [2], position "I'm OK" or "I'm not OK" by [3], loveworthy by [4], etc. In a multidimensional approach, selfattitude is presented as a hierarchical, internally structured system of particular components that reflect areas of personality manifestation and have different functions [5-10]. The traditional use of the "attitude" category implies cognitive, emotional, and behavioural components. Most often, self-attitude is understood as an emotional-value component of self-consciousness. It includes polymodal I-images (self-knowledge), as well as the emotions that they cause in the subject: for example, the physical and spiritual self, the real and ideal self [11], social looking-glass self [12], retrospective and prospective self [13], anti-self [6]. The stable position of an individual in relation to himself manifests both in external activity (social and subject activity) and intrapersonal processes.

Sardzhveladze [13] identified the most important functions of self-attitude: the "mirror" function (self- 
reflection, which underlies self-knowledge and selfcorrection); self-expression and self-realization; maintaining internal stability and coherence of the self; self-regulation and self-control; as well as a psychological defence. The self-position ensures interaction with the social world and intracommunication of the "subjects" of the individual's internal life. Self-attitude determines the area of significance in the self-sphere, centers the inner space of an individual, thus forming the vector of its selfdevelopment and self-fulfilment [14]. A recent revision of the healthy personality model [15] has confirmed the importance of clear and stable self-view, high selfesteem, and self-sufficiency.

The attitude to one's personality is formed based on basic knowledge about oneself laid in childhood, accumulated emotional and cognitive experience (a reflection of successes and failures), social comparisons, cultural norms and ideals, assessments acquired in the process of joint activities with other people. In [16] was showed that it is better to consider self-esteem not as a result of life outcomes (welfare in a relationship, work, and health) but as their cause. Thanks to longitudinal studies, today a general idea has been formed on the dynamics of global self-esteem during life: high in childhood, falls in adolescence and pre-adult age, increases steadily in adulthood, reaches a peak at about 50 years, then decreases sharply and rapidly in old age [17]. Within this general trend, selfesteem is a stable feature: people with relatively high (or low) self-esteem at one stage in their life are likely to have relatively high (or low) self-esteem after decades $[18,19]$.

The above concepts are based on the ideas of selfattitude as a personality trait - that is, stable behaviour patterns repeated in different situations. Like other personality traits, self-esteem can change, consistently, while demonstrating continuity in time [20]. There are, however, attempts to conceptualize self-attitude as a state, then it is endowed with the properties of situatedness, dynamism, and reactivity. Pantileev [21] explained that the dynamism of the structure of selfattitude ensures its general stability: at different times, a particular modality can act as a nuclear disposition (for example, in a situation of success, self-esteem takes the lead in the hierarchy, while self-acceptance does in a situation of failure). This is not just a product of self-consciousness, but an important factor in determining human behaviour. The internal dynamics of self-consciousness governs the establishment of interpersonal relationships, setting and achieving goals, behaviour in situations of choice, ways of resolving crisis situations. In addition, this is an important aspect of the subject's adequate involvement in psychocorrectional and psychotherapeutic measures.

The stability or instability of self-esteem is considered today as an important characteristic of a person, indicating its psychological well-being $[22,23]$. Convincing evidence has been accumulated that a targeted influence on self-esteem (for example, during therapy) has important life consequences. At the same time, experience has shown the ambiguity and limitations of predictive power: individual criteria of selfassessment are very specific in different people, and their effect on other psychological variables is also different $[5,24]$. There are some studies refuting the widespread belief that high self-esteem determines the social adaptation and life success of an individual. According to [25], it is not self-esteem that affects life satisfaction, but a more general factor - an inclination to positive effect. The theoretical study of self-esteem and the practical application of this knowledge will most likely remain the main issue of psychology for many years to come.

The study of the dynamics of self-esteem (as a personality trait and as a state) in the adult period of life, which has long been considered a period of stability, is of particular interest. Today, no one doubts that the processes of self-determination and re-selfdetermination take place in adulthood. This led to the identification of three periods of adulthood (early, middle, and later), the transitions between which are marked by crisis stages and are difficult for many people [26]. The features of self-concept at these turning points determine the future life path.

This study intends to trace the dynamics of global self-esteem and structural components of self-attitude at different stages of adulthood, as well as to identify signs of crisis periods.

\section{METHODOLOGY}

\section{Sample Description}

The survey involved 507 respondents aged 24 to 65 , of which 245 were men and 262 were women. According to the psychosocial approach [27], the sample covered the following stages: early adulthood from 24 to 34 years old (173 respondents), middle adulthood from 34 to 60 years old (253 respondents) and late adulthood (62 respondents over 60 years old). 
The main feature of adulthood is the maximum realization of the individual's physiological, cognitive, social, professional, and spiritual potential.

\section{Measurements}

Rosenberg Self-Esteem Scale (RSES) [2] is the most commonly used measure of global self-esteem in scientific research as "the individual's positive and negative attitude toward the self as a totality". This refers to a general sense of self-respect, the value of self. The questionnaire contains 10 points; five of them are formulated positively ("I feel that I'm a person of worth, at least on an equal plane with others"; "I feel that I have a number of good qualities"; "I take a positive attitude toward myself"; "On the whole, I am satisfied with myself"), five more contain negative formulations: "All in all, I am inclined to feel that I am a failure", "I feel I do not have much to be proud of" etc. (RSES text is available on the University of Maryland website and is approved for use in research). Respondents rate the proposed statements on a fourpoint Likert scale from the full agreement (3 points) to categorical disagreement ( 0 points); thus, the final score is measured on a scale from 0 to 30 . The possibility of using scales of a different dimension, as well as the need to refer to the norms of specific populations to distinguish between high and low selfesteem is indicated [28]. Since the tool was developed, its high reliability and validity have been repeatedly tested and confirmed in various ethnic, age, and clinical groups [29, 30], large-scale cross-cultural comparisons of self-esteem were made [31]. RSES was translated into Russian by Stolin [6]. However, data on its standardization and verification of psychometric qualities are still not known. Our work partially fills this gap by providing normative data for a large sample of adults.

The multidimensional structural-functional approach was implemented using the Self-Attitude Study Questionnaire (SASQ) created by Pantileev [21] in 1989 based on the theory of Stolin [6], who considers self-attitude as an emotional-value aspect of the sense of self. This tool is one of the most popular in Russianspeaking countries, has proven convergent, discriminant validity, and sufficient reliability (the correlation coefficient is from 0.72 to 0.93 for various scales with a retest interval of 10-14 days) [21]. The questionnaire contains 110 questions with two possible answers: "agree" - "disagree", aimed at assessing 9 scales that describe individual modalities of selfattitude.
1) The "Closedness" scale contains 11 items (for example: "I always show the same understanding of other people's problems as to my own ones"). In fact, this is a control "lie scale", which helps to identify and filter out cases when the respondent's answers are not dictated by reflection, but by a strong motivation for social approval. In addition, the measured property is related to the depth of self-consciousness, internal honesty, and self-criticism.

2) The "Self-Confidence" scale (14 items: "I am confident that you can rely on me in the most responsible matters" (+), "I am very hampered by a lack of energy, will and purposefulness" $(-))$ reveals a sense of competence and strength of self, attitude to self as a confident, independent and reliable person who has something to respect himself for.

3) The "Self-Management" scale (12 items: "What happens to me is my own doing (+)", "I'm sure that I am in my place (+)", "I quite clearly imagine what waits for me ahead " $(+)$ ) reflects the subjective experience of controllability and predictability of self. A high score corresponds to the person's self-image as the primary source of his own activity, the ability to effectively manage both external circumstances and himself.

4) The "Reflected Self-Attitude" scale (11 items: "I think that all my friends treat me with sympathy" $(+)$; There is probably something in my personality that can cause acute hostility in others (-)) describes the subjective perception of the existing relations, the person's idea that his personality and activity can cause respect, sympathy, approval, understanding in other people.

5) The "Self-Worth" scale (14 items: "You can say that I rate myself quite high" $(+)$, "Myself does not seem to be something worthy of deep attention (-)"; "Sometimes I doubt is it possible to truly love me" $(-)$ ) conveys a sense of self-worth, as well as perceived value to other people.

6) The "Self-Acceptance" scale (12 items: "Most often I approve my plans and actions", "Both my strengths and my weaknesses coexist quite peacefully in me," "I believe that sometimes it's not a sin to feel sorry for myself") allows evaluating the severity of feelings of sympathy 
for the self, agreement with one's inner impulses, accepting the self as it is.

7) The "Self-Attachment" scale (11 items: "It seems to me that I have established enough as a person, and therefore I don't spend much effort on becoming different in something" $(+))$ reveals a certain "conservative self-sufficiency": difficulty in changing self-image and unwillingness to change.

8) The "Internal Proneness to Conflict" scale (15 items: "Sometimes I misunderstand myself" (+), "I often, but unsuccessfully, try to change something in myself" $(+)$ ) determines the existence of internal doubts, disagreement with the self due to general negative self-attitude. The author calls this factor the most powerful among all 9 components and notes its connection with depressive states, frustration, psychosomatic complaints, an expression of inferiority and other indicators of mental distress [21].

9) The "Self-Blame" scale (10 items: "When I try to evaluate myself, I primarily see my shortcomings" (+), "I often provoke a feeling of irritation in myself" $(+)$, "To be honest, sometimes I'm very troublesome"(+)) describes the severity of negative emotions towards the self, increased attention to our own failures, shortcomings, and weaknesses.

\section{Data Processing}

"Raw" points on the scales were calculated and analysed. The reliability of the results was ensured using a control scale. A small number of respondents 19 people, i.e., $3.7 \%$ of the sample received high scores on the SASQ "Closedness" scale (10-11 points), which indicates a lack of reflection of ideas and feelings associated with the self-concept, as well as a tendency to give socially desirable answers. These cases were eliminated, but they took part in one stage of data processing - cluster analysis, where they formed a separate cluster.
Descriptive statistics tools $(\mathrm{M} \pm \mathrm{SD}$, Tests of Normality) were used to make sample test norms on the Rosenberg scale. A comparison of average indices in individual socio-demographic groups was carried out using Student's t-test for independent samples. By using the cluster analysis procedure, the sample was divided into groups differing in the level of self-esteem and the component structure of self-attitude. SPSS 19.0 was used for statistical data processing.

\section{RESULTS}

Among the results obtained, we note the RSES statistical standards, which were not known for the Ukrainian population until now. The adult sample data meets the criteria for normal distribution: statistics according to the Kolmogorov-Smirnov criterion (Lilliefors Significance Correction) is 0.035 for Sig. = 0.193 , the Shapiro-Wilk criterion is 0.995 for Sig. = 0.123 ). The average level of self-esteem is measured in the interval from 17 to 28 - see Table 1 .

Although there was no significant difference between the mean values of men and women $(t=-$ 0.765 at $p=0.444)$, the scatter of data in the subsamples significantly differs. Thus, the cut-off point of the low level of self-esteem is 16 points for men and 18 points for women (with a measuring scale from 0 to 30).

Comparison of the results of self-attitude in groups belonging to periods of early and middle adulthood showed an increase in the positiveness of self-attitude. The later adulthood sample is not representative enough, but it is important for tracking overall dynamics. Along with the growth of the positive aspects of self-esteem, the indicators of its negative components (self-blame) are also growing - see Table 2. In general, it can be stated that the individual's attitude toward himself becomes more emotionally expressive.

By dividing the maturity stage into 7-year periods (Figure 1), we can see that the age dynamics of each component of self-attitude is rather heterogeneous.

Table 1: Descriptive Statistics Based on the Results of the Rosenberg Self-Esteem Scale in the Ukrainian Sample

\begin{tabular}{|c|c|c|c|c|c|}
\hline & N & Mean & Std. Deviation & Minimum & Maximum \\
\hline \hline General sample & 488 & 22.70 & 5.43 & 8 & 30 \\
\hline Men & 240 & 22.63 & 6.18 & 10 & 30 \\
\hline Women & 248 & 22.77 & 4.60 & 29 \\
\hline
\end{tabular}


Table 2: Means of Self-Attitude in Representatives of Different Periods of Adulthood

\begin{tabular}{|c|c|c|c|c|c|c|c|}
\hline & \multicolumn{2}{|c|}{$\begin{array}{l}\text { Early Adulthood (25-34 } \\
\text { years), } N=173\end{array}$} & \multicolumn{2}{|c|}{$\begin{array}{c}\text { Middle Adulthood (34-60 } \\
\text { years), } \mathrm{N}=253\end{array}$} & \multicolumn{2}{|c|}{$\begin{array}{c}\text { Later Adulthood (over } 60 \\
\text { years) } N=62\end{array}$} & \multirow{2}{*}{$\begin{array}{c}\begin{array}{c}\text { Comparison in groups } \\
\text { of early and middle } \\
\text { adulthood }\end{array} \\
\text { T }\end{array}$} \\
\hline & $\mathbf{M}$ & SD & $\mathbf{M}$ & SD & $\mathbf{M}$ & SD & \\
\hline Lie Scale & 6.12 & 2.81 & 7.08 & 3.44 & 8.12 & 2.04 & $-2.073^{*}$ \\
\hline Self-confidence & 7.41 & 3.49 & 8.36 & 2.99 & 9.11 & 1.91 & $-2.077^{*}$ \\
\hline $\begin{array}{l}\text { Self-mana- } \\
\text { gement }\end{array}$ & 6.49 & 3.64 & 8.04 & 3.37 & 7.35 & 3.58 & $-3.647^{* *}$ \\
\hline $\begin{array}{l}\text { Reflected self- } \\
\text { attitude }\end{array}$ & 7.10 & 1.87 & 7.53 & 2.05 & 7.22 & 1.96 & -1.604 \\
\hline Self worth & 8.78 & 3.07 & 8.95 & 2.81 & 8.41 & 2.43 & -0.613 \\
\hline Self-acceptance & 7.66 & 4.12 & 8.30 & 3.67 & 9.07 & 3.22 & $-2.151^{*}$ \\
\hline Self-attachment & 6.82 & 2.03 & 7.25 & 1.96 & 8.02 & 1.74 & -1.638 \\
\hline $\begin{array}{c}\text { Internal } \\
\text { proneness to } \\
\text { conflict }\end{array}$ & 7.71 & 3.23 & 8.04 & 3.48 & 7.74 & 3.65 & -1.785 \\
\hline Self-blame & 5.67 & 3.07 & 6.96 & 2.64 & 6.51 & 2.34 & $-2.615^{\star *}$ \\
\hline $\begin{array}{l}\text { Rosenberg Self- } \\
\text { Esteem Scale }\end{array}$ & 21.64 & 5.74 & 23.07 & 6.08 & 24.2 & 5.65 & $-4.473^{\star *}$ \\
\hline
\end{tabular}

Note: *-marked are Student's t-test indicators significant at $p \leq 0.05 ;{ }^{* *}$ - at $p \leq 0.01$.

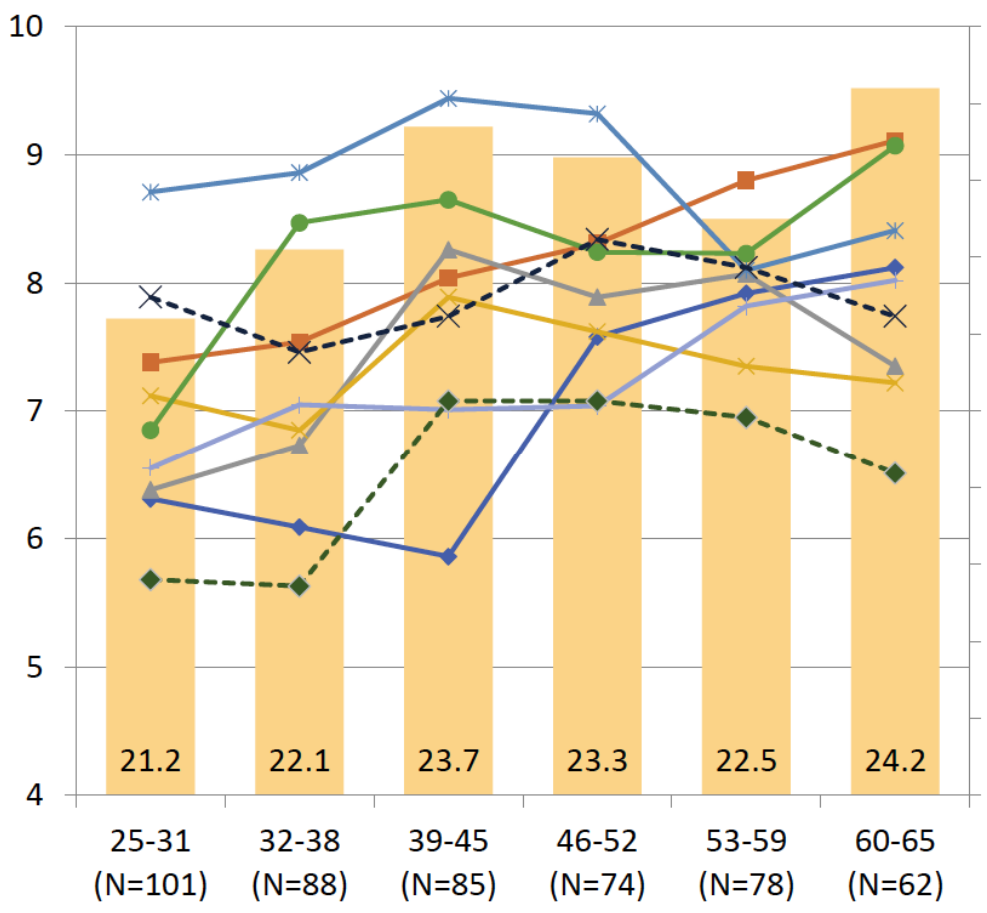

25

Rosenberg Self-

$24 \quad$ Esteem Scale

$23 \multimap$ Closedness

$22-$ Self-confidence

$21 \longrightarrow$ Self-management

$20 \div$ Reflected selfattitude

19

- Self-worth

18

- Self-acceptance

17

Self-attachment

$15 \quad-\because \nless--$ Internal proneness

to conflict

$--\triangleleft--$ Self-blame

Figure 1: Means of self-attitude in different age groups.

Only indicators of self-confidence and self-attachment grow steadily and evenly. The former is due to the formation of competence and self-efficacy in connection with gaining life experience. The latter with a regular increase in the rigidity of the self-concept and the unwillingness of a person to change even for the better, as evidenced by a sharp "leap" after 50 years. All other components of self-attitude have pronounced peaks and dips in different periods.

The curves in Figure 1 show the dynamics of selfattitude during adulthood, reflecting the regular stages of the life cycle. For example, some negativity of selfattitude (decline in experiencing self-management, self- 
acceptance) and the peak of self-blame at $46-52$ years can be explained by a normative crisis of the "middle age". Awareness of the limited life resource after 60 years determines the satisfaction of what has already been achieved, which is reflected in a decreased selfmanagement and increased self-acceptance.

It should be noted that the results obtained reflect not only the transformations of the self-concept in the process of age development but also the specifics of age cohorts - the general characteristics of people whose personality is formed in certain socio-cultural conditions that were influenced by the same historical events. Therefore, in particular, the sense of self-worth of young people is much higher than that of the older generation born in the USSR, whose individuality is formed under the conditions of subordination to collective interests. This generation (people over 50 ) is also characterized by the most pronounced social approval.

By using cluster analysis (hierarchical clustering, Average Linkage Between Groups), seven relatively homogeneous groups representing types of selfrelations in adulthood were identified in the general sample. Table 3 shows the most expressive distinguishing features of each cluster: high results are marked in bold, low results are underlined. Figure 2 gives an idea of the age composition of the clusters.

Cluster 1 represents subjects with super-high rates of social desirability (closedness of responses). They have pronounced positive self-esteem; however, these indicators are not reliable and rather indicate the severity of psychological defences, which makes the self-concept inadequate and rigid.

Clusters 2 and 3 combined respondents with fairly high rates of global self-esteem on the Rosenberg scale. Within this cluster branch, two subtypes with qualitative specifics can be differentiated: a) with a high level of self-worth, self-acceptance, and selfattachment (internally oriented components of selfesteem); b) with a high level of self-confidence, selfmanagement and reflected self-attitude (externallyoriented components of self-esteem).

Table 3 shows that the means on the Rosenberg scale provide for different structural contents. Most of the sample showed moderate self-esteem (Cluster 7), which may be due to the inexpressiveness of emotional reactions in relation to themself. In addition, a rather large proportion of respondents with an average positive overall self-esteem actually has an ambivalent self-attitude - a combination of simultaneously

Table 3: Features of Self-Esteem in Different Clusters (Mean Group Indicators)

\begin{tabular}{|c|c|c|c|c|c|c|c|c|}
\hline & $\begin{array}{l}\bar{D} \\
\frac{D}{\Delta} \\
\frac{D}{0}\end{array}$ & $\begin{array}{l}\text { N } \\
\stackrel{ \pm}{ \pm} \\
\stackrel{\Delta}{\Delta} \\
\frac{D}{U}\end{array}$ & $\begin{array}{l}m \\
\stackrel{m}{\Phi} \\
\stackrel{n}{0} \\
\frac{D}{U}\end{array}$ & $\begin{array}{l}+ \\
\stackrel{ \pm}{ \pm} \\
\frac{5}{D} \\
\frac{D}{U}\end{array}$ & 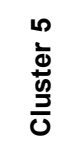 & 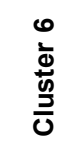 & $\begin{array}{l}\hat{N} \\
\bar{d} \\
\frac{\pi}{D} \\
\frac{D}{U}\end{array}$ & $\begin{array}{c}\text { Mean sample } \\
\text { indicator* }\end{array}$ \\
\hline $\mathbf{N}$ & 46 & 58 & 88 & 36 & 42 & 97 & 140 & \\
\hline$\%$ of the sample $(\mathrm{N}=507)$ & 9.1 & 11.4 & 17.4 & 7.1 & 8.3 & 19.1 & 27.6 & \\
\hline \multicolumn{9}{|c|}{ Distinctive features: } \\
\hline Closedness (Lie Scale) & 9.71 & 7.24 & 7.70 & $\underline{5.33}$ & 6.75 & $\underline{5.52}$ & 6.93 & 6.87 \\
\hline Self-confidence & 10.64 & $\underline{7.22}$ & 8.94 & 7.48 & $\underline{6.10}$ & 8.37 & 8.16 & 8.12 \\
\hline Self-management & 9.58 & 6.54 & 8.61 & $\underline{6.11}$ & $\underline{5.73}$ & 7.55 & 7.41 & 7.40 \\
\hline Reflected self-attitude & 9.05 & 6.80 & 7.89 & 7.15 & $\underline{5.74}$ & 7.66 & 7.27 & 7.34 \\
\hline Self-worth & 10.33 & 10.30 & 9.08 & 9.81 & $\underline{7.00}$ & $\underline{7.94}$ & 8.80 & 8.82 \\
\hline Self-acceptance & 9.85 & 9.79 & 8.52 & $\underline{6.56}$ & $\underline{5.94}$ & 7.67 & 8.39 & 8.17 \\
\hline Self-attachment & 8.77 & 7.98 & 7.23 & $\underline{5.59}$ & 6.73 & 7.19 & 7.25 & 7.19 \\
\hline Internal proneness to conflict & $\underline{6.37}$ & 7.46 & 7.76 & 8.11 & 9.19 & 8.17 & 7.67 & 7.88 \\
\hline Self-blame & $\underline{4.89}$ & 5.85 & 6.21 & 7.02 & 8.17 & 6.84 & 6.12 & 6.45 \\
\hline $\begin{array}{l}\text { Rosenberg Self-Esteem } \\
\text { Scale }\end{array}$ & 26.4 & 24.9 & 24.5 & 23.2 & $\underline{17.1}$ & 21.3 & 22.7 & 22.70 \\
\hline
\end{tabular}

Note: *-when calculating the average indicator, the sample took into account the data of 488 respondents (with the exception of those who showed excessive social desirability in the answers). 


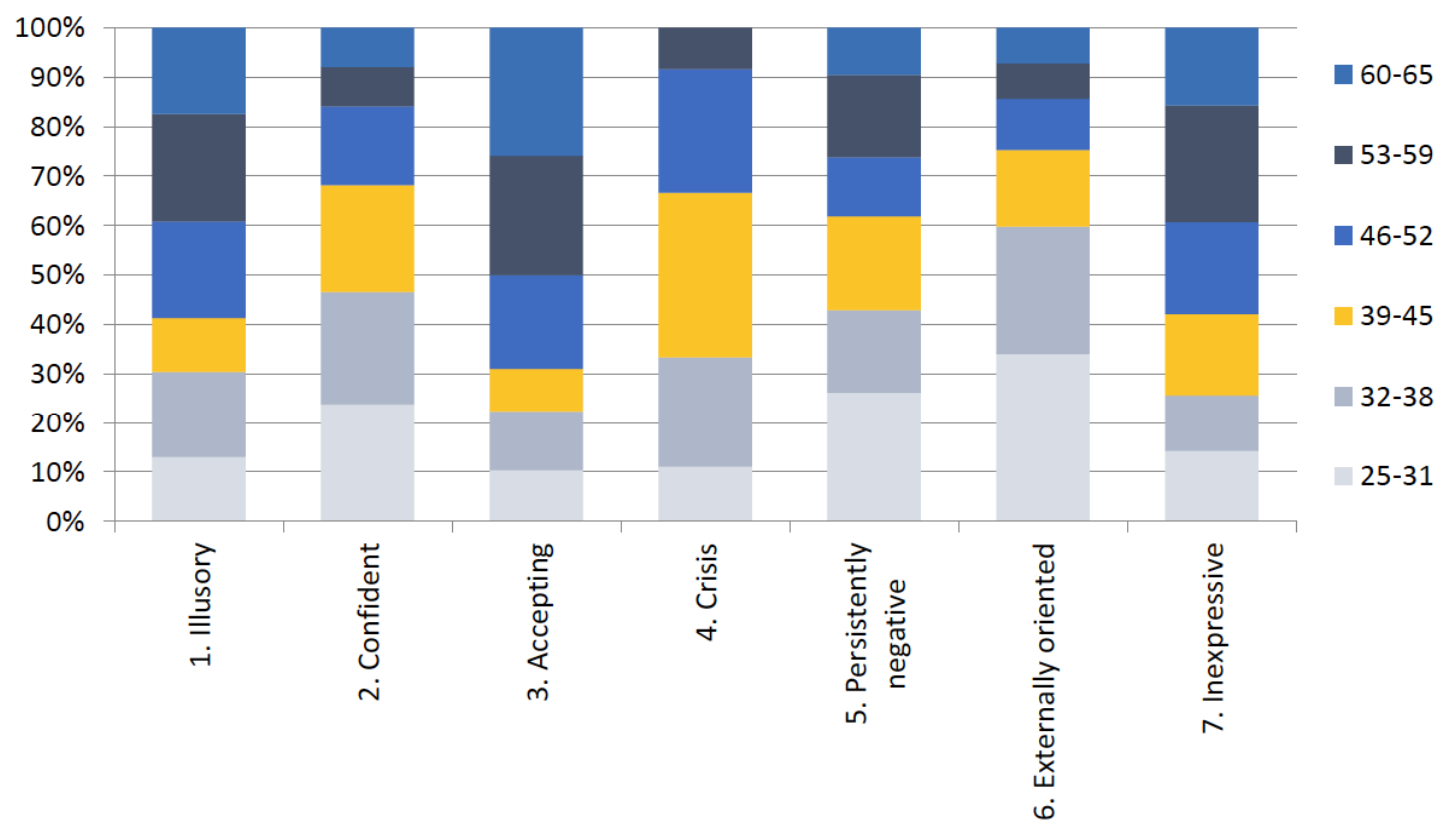

Figure 2: Cluster distribution by age subgroups, $\%$.

expressed negative and positive feelings about themselves. Two unstable, ambivalent types combined by a high level of self-criticism were identified. Cluster 4 distinguishes by high self-worth and a strong desire to change. Representatives of Cluster 6 have a reduced level of self-worth; they are focused on the expectation of a positive or negative attitude of other people. At the same time, $8.3 \%$ of respondents (Cluster 5) demonstrate stable persistently negative self-attitude.

\section{DISCUSSION}

The data obtained expand the understanding of the factor structure of self-esteem that existed earlier. So, Pantileev [21] singled out three secondary meta factors in the structure of the questionnaire he created: selfrespect, reflecting the assessment of the self in relation to social norms and values (Scales 1-4); autosympathy, expressing the individual's experiences of the self, an emotional feeling of attachment and disposition towards the self, not implying a comparison of the self with socially defined and individually acquired standards (Scales 5-7); self-abasement, representing the negative aspects of self-attitude (Scales 8 and 9). The latter factor can represent not only the real negative content of self-attitude but also a special kind of self-presentation aimed at the sympathy of others [21]. Earlier [32] was identified three types of selfattitude based on the clustering of the SASQ data: positive, negative, and conflict (ambivalent), which does not sufficiently reveal the qualitative identity of this mental phenomenon. Researchers in [33] laid the foundation for the typology of self-concept differentiation and self-concept clarity and found that older people are more likely to fall into a self-confident cluster, while young people are more likely to fall into a fragmented and tangled cluster. In the two-factor model, [9] presented self-esteem as a relationship between competence and worthiness; on this basis, in [34] were classified five types: positive, moderate, negative, self-centered, and success-centered.

The carried out work allowed us to detail the specific subtypes in the manifestations of positive and negative self-attitude, as well as externally and internally-centered self-esteem. Let us consider them in more detail in the context of previously known knowledge.

Cluster 1 was called "illusory-high self-esteem". Its main distinguishing characteristic is an extremely high level of social desirability combined with a pronounced rigidity of self-image. In this case, high self-esteem is, most likely, a consequence of low reflectivity, noncriticality in relation to yourself, as well as the manifestation of unconscious psychological defences aimed at avoiding internal conflict. Such a person expects a positive perception and attitude from other people and strives with all his might to demonstrate his well-being both to others and himself. The inclination to self-deception has deep psychological consequences and usually extends to many areas of human competence [35, 36]. He often positions himself as a highly spiritual, enlightened person, with possible 
manifestations of self-admiration. These cases of selfdeception are especially important (and complex) in practical work.

Cluster 3 is also characterized by some social desirability, but it is adaptive in nature and does not interfere with "honest" relationships with the self. High self-esteem is formed in relation to the external environment and expresses an assessment of the self in the context of socially approved criteria. In other words, a sense of self-worth is closely linked to the self's value for other people. The characteristics of this cluster correspond to the notions of self-esteem as a social phenomenon - the result of a comparison of the real self and the reference ideas of a successful and effective individual embedded in an ideal self-image [2, 11]. This type is characterized by a rather pronounced tendency to self-change and self-development, the source of which is the challenges and requirements of the external environment, life situation. We called it "confidently-adaptive type". This type of self-esteem prevails in the early and middle stages of adulthood (up to 45 years).

For the "self-accepting type" (Cluster 2), the main characteristics are a sense of self-worth, selfacceptance, and self-understanding. The influence of social criteria of well-being and ideal self is reduced (compared to Cluster 2). Such people are quite aware of their shortcomings, failures, and weaknesses, but accept them as the reverse side of their merits and successes. The general attitude towards the self is positive, even a little self-contented. Self-acceptance is accompanied by some rigidity of the self-concept, unwillingness to change even for the better. You can interpret this combination of signs as a mechanism for maintaining high self-esteem and protection from negative emotions in situations of the threat of loss of self-esteem. This assumption is confirmed by the fact that almost half of the cluster were respondents over 50 years of age.

Earlier, in [21] was explained that the experiences underlying the "autosympathy" factor are not associated with personal manifestations of the subjects. Thus, in [1] noted clear signs of selfprotection in older people who recognize deterioration in the processes of memory, attention, thinking (a lower level of self-esteem), while their attitude to themselves remains the same and even improves. The phenomenon of mismatch of self-esteem and selfattitude is observed at all stages of adulthood from 21 to 74 years when these qualities are definitely shaped.
Interoceptive orientation of the personality is a natural mechanism for maintaining positive self-concept with a decrease in external activity [37]. It can also be internal calmness against the background of objectively high personal, social, and professional achievements when satisfaction of the leading needs makes them subjectively insignificant. It should be recognized that this option of psychological well-being is not very popular in a modern Western society focused on the cult of "success".

As a rule, an individual actively protects selfattitude. In work [6] was suggested the existence of a "protective" mechanism embedded in the multidimensional structure of self-attitude: in case of a deficiency of one of the components, other aspects begin to play a leading (compensating) role. For example, low self-respect is offset by increased autosympathy. According to [8], the main ways to maintain self-worth in adulthood are formed in childhood based on early emotional experience, including a traumatic one. To maintain self-respect, a person chooses areas in which he feels comfortable in the conditions of success or failure: appearance, competition, approval of others, virtue, religious faith, prestige, support of friends or family, romantic relationships, etc. [8, 38]. Thus, Clusters 2 and 3 represent two alternative ways to achieve positive selfesteem, which are traditionally represented in Western and Eastern culture.

In our opinion, Cluster 4 is unstable, temporary. It brought together $7.1 \%$ of the respondents, of whom one third are representatives of the age cohort of 39-45 years old (while not a single person is over 60). We believe that this combination of characteristics reflects the transformational processes of self-consciousness that are characteristic of the age crisis of 40 years and other life situations accompanied by a revision of one's life position. A distinctive feature of self-attitude in this state is increased internal honesty, openness towards the self, and a strong desire for self-change changes. An increased level of self-worth paradoxically combines with self-dissatisfaction. A person feels dependent on external circumstances, but at the same time blames himself for his shortcomings and failures. Judging by the data obtained, these inconsistencies give rise to a strong internal tension, which is realized in external and internal activity, which is intended to correspond to one's ideal ideas. The feeling of uncontrollability and negative emotions in one's address is temporary conditions in this case - these are negative stimuli that trigger some ripen life changes. A person makes active 
efforts to return to a comfortable, positive self-concept, in order to reach a state where their "real self" will truly correspond to the desired ideal idea.

The observed decrease in the means of general self-esteem at the stage of transition to late maturity is confirmed by previous studies [29]. It is known that age and life crises are accompanied by a restructuring of self-consciousness and self-concept - this is their essence: a person realizes the meaning of his existence, loses consistent ideas about himself and others, reconsiders the possibility of realizing important values. The transformations taking place at this time affect basic attitudes and beliefs, including about oneself as a "starting point" of one's life position [37]. According to [39], at 25-29 years, the determining component of a life position is a sense of purposefulness, awareness, and implementation of one's life plans. After 40 years, the person's focus on comprehension of his inner world, the desire for selfimprovement, in line with a decrease in the sense of control over his own life, significantly increases. Our results confirm these trends.

According to [26], a characteristic feature of age crises of adulthood is a feeling of regret: at earlier stages, it stimulates the person to make useful changes in his life, at later stages, when changes are impossible, it helps to accept himself and his environment as they are. Self-identification of an adult person depends on the social roles that he performs. It should be remembered that in early adulthood, a person first experiences separation from his parents, then focuses on creating a family and raising children, building a professional career (these are the usual, socially expected areas of self-realization and selffulfilment of a person). In the later stages of adulthood, the self-concept changes again in connection with the separation of one's children, as well as the need to care for aging parents. All these factors obviously influence the self-centering and reflection of one's own needs.

The obtained results raise the issue of clarity and stability of self-esteem as a specific personality trait an important marker of psychological well-being. This problem is being actively discussed $[22,23,40]$ but is still far from being resolved.

In this context, Cluster 6 is of theoretical and practical interest. This type of self-attitude is also ambivalent (that is, unstable), although to a lesser extent than the "crisis-transformational" Cluster 4. In this case, the positively reflected self-attitude is combined with reduced self-worth - the individual underestimates his capabilities. He doubts the value of his personality and is estranged from his inner world. This combination provides internal tension, which can be both constructive and destructive. Since this type is predominant among young people under 35 years of age, we believe that such self-attitude reflects a persistent desire for success based on external evaluation criteria, without a sufficient understanding of one's internal aspirations. The efforts are not aimed at changing oneself, but at social achievements, monitoring and improving life circumstances. Upon reaching the goal, such a type can be transformed into a self-confident type (Cluster 2 is closest to it in the clustering tree); in case of failure, it will become a selfreproaching type.

In research [41] author formulates the criteria for the optimal life position of an individual - "an involved focused life", which is based on a neutral-positive attitude towards oneself and the value of the self. However, there is some dissatisfaction with the leading needs of an individual. The author explains that the gap between assessing the real situation and ideas about what is desired is a source of development and growth that makes a person truly happy. It should be remembered that external criteria (academic, social, financial success, attractive appearance, etc.) require a constant confirmation from others, are unreliable as a basis for self-esteem, and therefore are associated with higher costs and vulnerability $[42,43]$. Due to these foundations' instability, a person's self-esteem fluctuates along with daily successes and failures [34, 38]. Striving for social success not supported by selfworth can lead to internal conflicts.

In contrast to the ambivalent types of self-esteem with embedded development potential, Cluster 5 - the self-reproaching type - is a little dependent on age. It represents the traditional understanding of negative self-attitude as self-dissatisfaction, pronounced inferiority in subjectively significant areas of life, doubts about one's ability to arouse respect and acceptance of others. The feeling of conflict between the self and selfblame prevail. Unlike other clusters, negative attitudes are not compensated and are not balanced by positive ones. Neutral assessments on the of Confidence, Closedness and Self-management Scales suggest that such a person may look quite prosperous (unlike the crisis type, which tends to depart consciously from the generally accepted notions of "right" and "good"). It is important to understand for practical work that negative 
attitudes towards oneself are stable and rigid - a person does not consider himself capable of changes or does not see such an opportunity, he is also not capable of internal dialogue. It is known that the attitude toward self-blame is accompanied by persistent negative effects: anxiety, inner tension, readiness to perceive negative emotions in one's address, emphasizing difficulties [21]. We called this cluster "sustainable self-alienation".

It should be noted that such an attitude may be due to negative self-presentation tactics that are beneficial for the individual (but even in this case, there are significant internal prerequisites for such manifestations). A self-presentation strategy is an important psychological resource for overcoming life stress and developmental problems in adulthood [44].

\section{CONCLUSIONS}

The data obtained confirmed an increase in selfesteem during the maturity period, but multidirectional structural changes were revealed. A significant increase in self-confidence and self-management is also accompanied by an increase in self-blaming. In general, the attitude towards oneself becomes more emotionally expressive with age, as for both positive and negative components: a mature person reflects more and takes everything to heart that relates to himself. The subjective significance of the various components of self-attitude is especially pronounced in times of crisis. A typological diversity of types of selfesteem was revealed, among which unstable types are especially interesting. The classification, based on the multidimensional structure of self-relationship, combines the idea of its internal and external sources with the phenomenology of self-attitude as positive, negative, or ambivalent. Formulated descriptions of types are useful in practical work. It is important to understand that high self-esteem can be combined with psychological distress, and among cases of low selfesteem, there are often potential opportunities for personal growth and development.

The obtained results lay the foundation for further theoretical and practical research, where the mechanisms of protecting self-esteem and its destabilization in experiencing age crises are of particular interest.

\section{ETHICAL CONSIDERATION}

All respondents gave informed consent to participate in the study, and they were guaranteed the confidentiality of personal data and their use for scientific purposes only.

\section{ACKNOWLEDGEMENT}

We express our sincere gratitude to the teams and managers of the National Academy of Internal Affairs, Rive State University of the Humanitarians, Ternopil Volodymyr Hnatiuk National Pedagogical University, and the Taras Shevchenko National University of Kyiv for a comfortable environment for research, as well as support.

\section{REFERENCES}

[1] Borozdina LV. The essence of self-esteem and its relationship with the self-concept. Moscow University Psychology Bulletin 2011; 1: 54-65.

[2] Rosenberg M. Society and the adolescent self-image. Middletown, CT: Wesleyan University Press 1989.

[3] Harris T. I'm ok-you're OK. New York: Galahad Books 2004.

[4] Epstein S. Cognitive-experiential theory: An integrative theory of personality. Oxford: Oxford University Press 2014 https://doi.org/10.1093/acprof:osobl/9780199927555.001.000 1

[5] Branden N. The six pillars of self-esteem. New York: Bantam 1994.

[6] Stolin VV. Psychodiagnostics of self-awareness. In: Bodalev AA, Stolin VV, Avanesov VS, editors. General psychodiagnosis. Chapter 9. St. Petersburg: Rech 2000; pp. 349-415.

[7] Coopersmith S. Revised Coopersmith self-esteem inventory manual. Redwood: Mind Garden 2002.

[8] Crocker J. The costs of seeking self-esteem. J Soc Issues 2002; 58(3): 597-615.

https://doi.org/10.1111/1540-4560.00279

[9] Mruk CJ. Defining self-esteem as a relationship between competence and worthiness: How a two-factor approach integrates the cognitive and affective dimensions of selfesteem. Polish Psychological Bulletin 2013; 44(2): 157-64. https://doi.org/10.2478/ppb-2013-0018

[10] Rentzsch K, Wenzler MP, Schuetz A. The structure of multidimensional self-esteem across age and gender. Personality and Individual Differences 2016; 88: 139-47. https://doi.org/10.1016/j.paid.2015.09.012

[11] Rogers C. On becoming a person: A therapist's view of psychotherapy. London: Constable 1961.

[12] Cooley $\mathrm{CH}$. Human nature and the social order. New York: Charles Scribner's Sons 1922.

[13] Sargveladze NI. Personality and its interaction with the social environment. Tbilisi: Metzniereba 1989.

[14] Garanina ZG, Balyaev SI, Ionova MS. The role of selfattitude in the personal and professional development of high school students. The Education and Science Journal 2019; 21(1): 82-96.

https://doi.org/10.17853/1994-5639-2019-1-82-96

[15] Bleidorn W, Hopwood CJ, Ackerman RA, Witt EA, Kandler C Riemann R, Samuel DB, Donnellan MB. The healthy personality from a basic trait perspective. J Pers Soc Psychol 2020; 118(6): 1207-25. https://doi.org/10.1037/pspp0000231

[16] Orth U, Robins RW, Widaman KF. Life-span development of self-esteem and its effects on important life outcomes. J Pers Soc Psychol 2012; 102(6): 1271-88. https://doi.org/10.1037/a0025558 
[17] Robins RW, Trzesniewski KH, Tracy JL, Gosling SD, Potter J. Global self-esteem across the life span. Psychol Aging 2002; 17(3): 423-34 https://doi.org/10.1037/0882-7974.17.3.423

[18] Kuster F, Orth U. The long-term stability of self-esteem: Its time-dependent decay and nonzero asymptote. Pers Soc Psychol Bull 2013; 39(5): 677-90.

https://doi.org/10.1177/0146167213480189

[19] Orth U, Robins RW. The development of self-esteem. Curr Dir Psychol Sci 2014; 23 (5): 381-7. https://doi.org/10.1177/0963721414547414

[20] Chung JM, Robins RW, Trzesniewski KH, Noftle EE, Roberts BW, Widaman KF. Continuity and change in self-esteem during emerging adulthood. J Pers Soc Psychol 2014; 106(3): 469-83. https://doi.org/10.1037/a0035135

[21] Pantileev SR. Methodology for the study of self-relationship. Moscow: Smysl 1993.

[22] Kernis $\mathrm{MH}$. Measuring self-esteem in context: The importance of stability of self-esteem in psychological functioning. J Pers 2005; 73: 1569-605. https://doi.org/10.1111/j.1467-6494.2005.00359.x

[23] Chabrol H, Rousseau A, Callahan S. Preliminary results of a scale assessing instability of self-esteem. Can J Behav Sci 2006; 38(2): 136-41.

https://doi.org/10.1037/cjbs2006003

[24] Bremer V, Funk B, Riper H. Heterogeneity matters: Predicting self-esteem in online interventions based on ecological momentary assessment data. Depress Res Treat 2019; 2019: 3481624 https://doi.org/10.1155/2019/3481624

[25] Coffey JK, Warren M. Comparing adolescent positive affect and self-esteem as precursors to adult self-esteem and life satisfaction. Motiv Emot 2020.

https://doi.org/10.1007/s11031-020-09825-7

[26] Berk LE. Exploring lifespan development. 4th ed. Boston: Pearson 2018.

[27] Newman BM, Newman PR. Development through life: A psychosocial approach. Boston: Cengage Learning 2014.

[28] Using the Rosenberg Self-Esteem Scale. University of Maryland, Department of Sociology; 2020. [cited 2020 June 28]. Available from: https://socy.umd.edu/about-us/usingrosenberg-self-esteem-scale

[29] Sinclair SJ, Blais MA, Gansler DA, Sandberg E, Bistis K, LoCicero A. Psychometric properties of the rosenberg selfesteem scale: Overall and across demographic groups living in the united states. Eval Health Prof 2010; 33(1): 56-80. https://doi.org/10.1177/0163278709356187

[30] Wongpakaran T, Wongpakaran N. A comparison of reliability and construct validity between the original and revised versions of the Rosenberg self-esteem scale. Psychiatry Investig 2012; 9(1): 54-8.

https://doi.org/10.4306/pi.2012.9.1.54

[31] Schmitt DP, Allik J. Simultaneous administration of the Rosenberg self-esteem scale in 53 nations: Exploring the universal and culture-specific features of global self-esteem. J Pers Soc Psychol 2005; 89(4): 623-42.

https://doi.org/10.1037/0022-3514.89.4.623
[32] Kochetkova TN. The specifics of the types of self-relationship of a person depending on the severity of emotional and cognitive components [PhD dissertation]. Khabarovsk 2007.

[33] Diehl M, Hay EL. Self-concept differentiation and selfconcept clarity across adulthood: associations with age and psychological well-being. Int J Aging Hum Dev 2011; 73(2): 125-52.

https://doi.org/10.2190/AG.73.2.b

[34] Molchanova ON, Sokolova Tlu. The role of self-esteem in responding to situations of "threat of self". Vestnik of Saint Petersburg University. Psychology 2019; 9(2): 138-54. https://doi.org/10.21638/spbu16.2019.203

[35] Kruger J, Dunning D. Unskilled and unaware of it: How difficulties in recognizing one's own incompetence lead to inflated self-assessments. J Pers Soc Psychol 1999; 77(6): 1121-34.

https://doi.org/10.1037/0022-3514.77.6.1121

[36] Dunning D. The dunning-kruger effect: On being ignorant of one's own ignorance. Adv Exp Soc Psychol 2011; 44: 24796.

https://doi.org/10.1016/B978-0-12-385522-0.00005-6

[37] Tavrovetska NI. The design of life positivities is the same as the crises of life. Actual Problems of Psychology. Collection of Scientific Papers of G. S. Kostiuk Institute of Psychology NAPS Ukraine 2018; 1(14): 298-310.

[38] Nekrasova TYu. Features of response in a "threat of self" situation depending on the type of self-esteem $[\mathrm{PhD}$ dissertation]. Moscow 2015.

[39] Bocheliuk VY. The formation of life positions in different socialization stages of adult personality. Scientific Bulletin of Kherson State University. Series "Psychological Sciences" 2020; 1: 109-18. https://doi.org/10.32999/ksu2312-3206/2020-1-15

[40] Campbell JD, Assanand S, DiPaula A. The structure of the self-concept and its relations to psychological adjustment. $J$ Pers 2003; 71: 115-40. https://doi.org/10.1111/1467-6494.t01-1-00002

[41] Tavrovetska NI. Empirical analysis of the significant characteristics of an individual's life position. Problems of Modern Psychology 2018; 41: 345-59. https://doi.org/10.32626/2227-6246.2018-41.345-359

[42] Crocker J, Luhtanen RK. Level of self-esteem and contingencies of self-worth: Unique effects on academic, social, and financial problems in college students. Pers Soc Psychol Bull 2003; 29(6): 701-12. https://doi.org/10.1177/0146167203029006003

[43] Crocker J, Canevello A. Consequences of self-image and compassionate goals. In: Devine PG, Plant A, editors. Advances in Experimental Social Psychology. New York: Elsevier 2012; pp. 229-77.

https://doi.org/10.1016/B978-0-12-394286-9.00005-6

[44] Diehl M, Hay EL. Contextualized self-representations in adulthood. Personality 2007; 75(6): 1255-83. https://doi.org/10.1111/j.1467-6494.2007.00475.x

\section{DOI: https://doi.org/10.6000/2292-2598.2020.08.04.15}

(c) 2020 Kostytsky et al.; Licensee Lifescience Global.

This is an open access article licensed under the terms of the Creative Commons Attribution Non-Commercial License (http://creativecommons.org/licenses/by-nc/3.0/) which permits unrestricted, non-commercial use, distribution and reproduction in any medium, provided the work is properly cited. 